\title{
Preclinical medical students' usage of electronic devices in lectures: A cross-sectional study
}

\author{
Rex W. H. Hui ${ }^{1}$, Sheona S. N. Leung ${ }^{1}$, Tiffany L. C. Cheung ${ }^{1}$, Edwin W. M. Chu ${ }^{1}$, \\ Jason C. Y. Fong ${ }^{1}$, Ivan H. W. Lau ${ }^{1}$, Victor C. Y. Leung ${ }^{1}$, Eugene Leung ${ }^{1}$, \\ Kimberly K. Y. Yip ${ }^{1}$, Vivian Yung1, Coco K. Chen², Lap Ki Chan ${ }^{3 *}$ \\ ${ }^{1}$ Li Ka Shing Faculty of Medicine, The University of Hong Kong, ${ }^{2}$ School of Public Health, Li Ka Shing Faculty of Medicine, \\ The University of Hong Kong, ${ }^{3}$ Institute of Medical and Health Sciences Education, Li Ka Shing Faculty of Medicine, \\ The University of Hong Kong, Hong Kong SAR, China
}

\section{ABSTRACT}

Background and Objectives: Electronic devices such as laptops, tablets, and smartphones are commonly used in clinical clerkships, problem-based learning, and practicals. However, there is limited literature on electronic device usage in medical lectures. This study aimed to (1) assess preclinical medical students' pattern and reason for electronic device usage in lectures and (2) assess the effect of lecture content and student factors on device usage. Materials and Methods: This was a cross-sectional study from the year 1 to 3 medical students of the Li Ka Shing Faculty of Medicine, The University of Hong Kong. The data was collected through self-administrated questionnaires. The questionnaire was distributed twice to the same cohort of students, once after their basic medical science lectures, another after humanities lectures. Categorical variables were compared by Chi-squared test or Fisher's exact test; continuous variables were compared by Mann-Whitney U-test or Kruskal-Wallis H-test. Results: Five hundred and seventy-nine valid questionnaires were collected. Students spent more time on electronic devices for learning in science lectures when compared with humanities lectures $(P<0.001)$. In contrast, students spent more time for nonlearning purposes in humanities lectures $(P<0.001)$. In science lectures, the mode of admission to medical school $(P<0.05)$ and year of study $(P<0.001)$ were factors affecting the device usage. Conclusions: Lecture content, mode of admission, and year of study have a significant impact on the electronic device usage in preclinical medical lectures. Appropriate interventions are necessary to help the students make better use of their devices and decrease the time spent on nonlearning purposes, particularly in humanities lectures.

Keywords: Lectures, smartphones, undergraduate medical education

\section{INTRODUCTION}

Electronic devices including laptops, tablets, and smartphones are gaining popularity in society and are commonly used in tertiary education. ${ }^{[1,2]}$ Usage of

*Address for correspondence:

Dr. Lap Ki Chan, L1-45, 1/F, Laboratory Block, 21 Sassoon Road,

Pokfulam, Hong Kong SAR, China.

E-mail: lapki@hkucc.hku.hk

\begin{tabular}{|l|l|}
\hline \multicolumn{2}{|c|}{ Access this article online } \\
\hline Quick Response Code & Website: \\
\hline & www.digitmedicine.com \\
\cline { 2 - 2 } & \\
\hline
\end{tabular}

electronic devices and e-learning resources is also widely accepted in medical education. Multiple studies and programs have been performed to assess or implement electronic device usage in medical education. Areas covered include clinical clerkship teaching, ${ }^{[3,4]}$ clinical skills learning, ${ }^{[5,6]}$ problem-based learning, ${ }^{[7]}$ practicals, ${ }^{[8,9]}$

This is an open access article distributed under the terms of the Creative Commons AttributionW-NonCommercial-ShareAlike 3.0 License, which allows others to remix, tweak, and build upon the work non-commercially, as long as the author is credited and the new creations are licensed under the identical terms.

For reprints contact: reprints@medknow.com

How to cite this article: Hui RW, Leung SS, Cheung TL, Chu EW, Fong JC, Lau $\mathrm{IH}$, et al. Preclinical medical students' usage of electronic devices in lectures: A cross-sectional study. Digit Med 2016;2:64-71. 
Hui, et al.: Medical students' mobile device usage

and the teaching of specific specialties such as surgery and pathology. ${ }^{[10,11]}$ Most of the published literature on device usage in medical education are based on clinical years or postgraduate medical teaching, and there is limited literature about electronic device usage in lectures in the preclinical stage.

The pattern of usage has also been studied. Studies have suggested the usage of electronic devices for note-taking ${ }^{[12]}$ and to search for academic resources. ${ }^{[4]}$ The use of handheld devices for accessing electronic databases such as "UpToDate" and "Best Practice" is also increasingly popular. ${ }^{[13]}$ Newer innovations such as usage of social media ${ }^{[14,15]}$ and interactive information sharing for lectures ${ }^{[16]}$ have been proposed. However, concerns have also been raised about electronic devices being a distraction and how students may use electronic devices for nonlearning purposes. ${ }^{[2,7,17,18]}$ Students may multitask on their electronic devices and could be disturbed by other activities. ${ }^{[1]}$ Other challenges raised include superficial learning and not knowing how to appropriately use the resources. ${ }^{[17]}$ There are also concerns that the heavy reliance on these electronic resources may lead to information overload and omission of important core knowledge. ${ }^{[13]}$

The literature elicits that electronic devices have shown benefits in medical education and received generally positive comments from students. However, arguments have been made against the usage of electronic devices. The usage rate of electronic devices in medical education is high and electronic devices are widely accepted tools for medical lectures. Yet, the data on device usage in preclinical medical students are limited. This study will provide an understanding of the electronic device usage pattern of preclinical medical students in lectures. The objectives of the study are (1) to identify the pattern and reason of electronic device usage in preclinical medical lectures and (2) to identify whether lecture content (basic medical science versus humanities) and student factors will affect electronic device usage in preclinical medical students.

\section{MATERIALS AND METHODS}

\section{Study population}

The sample population encompassed year 1-3 undergraduate Bachelor of Medicine and Bachelor of Surgery (MBBS) students of the Li Ka Shing Faculty of Medicine, The University of Hong Kong (HKU) in the 2014-2015 academic year. There are two modes of admissions into the HKU MBBS curriculum - Joint
University Programmes Admissions System (JUPAS) and non-JUPAS. JUPAS refers to students who have completed secondary education in local schools. Non-JUPAS admission encompasses degree holders, students from overseas schools, and students from international schools (schools in Hong Kong that adopt international curriculum rather than the local Hong Kong curriculum).

The HKU MBBS curriculum is system-based and problem-based. It is horizontally integrated, with system-based blocks in the year 1-3. Problem-based learning occupies about $25 \%$ of the timetable in that period, while students also need to attend lectures and practicals. The MBBS curriculum is also vertically integrated with early clinical exposure starting from year 1 and later revisit of basic sciences. Since classes from year 4 to 6 mostly take place in clinical settings, the first 3 years are called the preclinical years in this study (despite the fact that clinical exposure starts from year 1).

\section{Procedure}

The data was collected in the form of a self-administered questionnaire filled in by the students. The questionnaires were distributed to students immediately after their lectures. Students were invited to fill in the questionnaires referring to their electronic device usage in the lecture they just finished. The questionnaire was distributed twice to each of the three cohorts of students (i.e., year 1-3), once after their basic medical science lectures (such as anatomy, biochemistry, microbiology, physiology, or pharmacology) and another after humanities lectures (such as medical ethics or humanities). Each of the lectures lasted for approximately $60 \mathrm{~min}$.

The questionnaire used in this study was adopted and edited from a previous study by Chan et al..$^{[7]}$ The questionnaire encompassed three parts: (1) background information of students (year of study, mode of admission to medical school), (2) type of lecture that was just conducted (basic medical science or medical humanities), and (3) pattern and reason of electronic device usage in lecture.

\section{Statistical analysis}

Data were analyzed using the SPSS version 21 (SPSS Inc, Chicago, IL). Descriptive statistics were expressed as number (percentage). Categorical variables were compared by Chi-squared test or Fisher's exact test; continuous variables were compared by Mann-Whitney U-test or Kruskal-Wallis H-test. 
Hui, et al:: Medical students' mobile device usage

\section{Ethical considerations}

Participation was voluntary and written consent was obtained. No identifiable information was collected. The study was approved by the Institutional Review Board of the HKU/Hospital Authority Hong Kong West Cluster (IRB reference number: UW 14-617).

\section{RESULTS}

In total, 579 valid questionnaires were analyzed. Three hundred and eighty-nine questionnaires were completed in basic medical science lectures, and 190 questionnaires were completed in humanities lectures. It was noted that the number of questionnaires collected in humanities lectures was smaller than that in basic medical science. This could be due to the lower attendance rate in humanities lectures, hence the smaller number of respondents. A summary of the data is given in Table 1.

\section{Time spent on electronic devices}

In the questionnaires, the students reported the time they spent on their electronic devices for learning and nonlearning purposes. Each lecture lasted for an hour, so the time range that they spent was 0-60 min. Students could multitask and simultaneously perform learning and nonlearning tasks, therefore they were allowed to fill in a maximum time of $60 \mathrm{~min}$ for learning and $60 \mathrm{~min}$ for nonlearning. Students with no usage of electronic devices at all were marked as $0 \mathrm{~min}$ for both categories.

\section{Basic medical science lectures}

In basic medical science lectures, year of study had no significant effect on the time spent on electronic devices for learning purposes $\left(\chi^{2}[2, N=389]=1.14\right.$, $P=0.565)$. In contrast, the year of study was significantly associated with the time of device usage for nonlearning purposes $\left(\chi^{2}[2, N=389]=17.85, P<0.001\right)$. Follow-up pairwise comparison showed that there were significant

Table 1: Demographics of respondents

\begin{tabular}{lcc}
\hline & $\begin{array}{c}\text { Basic medical science } \\
\text { lectures }(\boldsymbol{n}=389)\end{array}$ & $\begin{array}{c}\text { Humanities } \\
\text { lectures }(\boldsymbol{n}=190)\end{array}$ \\
\hline $\begin{array}{l}\text { Year of study (\%) } \\
\text { Year 1 }\end{array}$ & $159(40.87)$ & $46(24.21)$ \\
Year 2 & $110(28.28)$ & $57(30.00)$ \\
$\quad$ Year 3 & $120(30.85)$ & $87(45.79)$ \\
Mode of admission & & \\
to medical school (\%) & & $127(66.84)$ \\
$\quad$ JUPAS & $270(69.41)$ & $63(33.16)$ \\
$\quad$ Non-JUPAS & $119(30.59)$ &
\end{tabular}

JUPAS refers to students admitted to medical school through Hong Kong local secondary schools. Non-JUPAS admission encompasses all other routes of admission (international schools, overseas schools, degree holders). JUPAS: Joint University Programmes Admissions System differences in time spent between year 1 and year 2 students $(P<0.001)$ and between year 1 and year 3 students $(P<0.05)$. The time spent on nonlearning purposes in year 1 students was greater than the time in year 2 and 3 students, respectively.

The effect of mode of admission (JUPAS and non-JUPAS) was also analyzed. The time spent on learning purposes was significantly greater in non-JUPAS students than in JUPAS students $(U=18074.50, P<0.05)$. Mode of admission had no significant effect on the time spent on nonlearning purposes $(U=15551.00, P=0.600)$.

\section{Humanities lectures}

In humanities lectures, the year of study and mode of admission both had no significant effect on the electronic device usage time.

\section{Comparing basic medical science and humanities lectures}

Comparing science and humanities lectures, students spent significantly more time on their electronic devices for learning purposes in science lectures $(U=26450$, $P<0.001)$. On the other hand, students spent significantly more time on nonlearning purposes in humanities lectures $(U=47867.50, P<0.001)$.

\section{Reason for usage}

In the questionnaire section on the reason for usage, students were allowed to select more than one option as students may multitask and use electronic devices for different purposes in the same lecture.

In basic medical sciencelectures, 299 (76.86\%) respondents reported the usage of electronic devices. Of the students who used electronic devices, $196(65.56 \%)$ used devices for viewing lecture materials, $178(59.53 \%)$ for taking notes, $144(48.16 \%)$ for researching, $47(15.72 \%)$ for reading reference materials, and seven $(2.34 \%)$ for recording the lecture content [Figure 1]. For nonlearning purposes, $151(50.50 \%)$ used electronic devices to access social media, $47(15.71 \%)$ for extracurricular activities, 99 (33.11\%) for accessing E-mails, 141 (47.16\%) for instant messaging, $54(18.06 \%)$ for entertainment, and $34(11.37 \%)$ for reading the news [Figure 2].

In humanities lectures, 151 (79.47\%) respondents reported the usage of electronic devices. Of the students who used electronic devices, $66(43.71 \%)$ used devices for viewing lecture materials, $42(27.82 \%)$ for taking notes, $37(24.50 \%)$ for researching, and $15(9.93 \%)$ for 
Hui, et al.: Medical students' mobile device usage

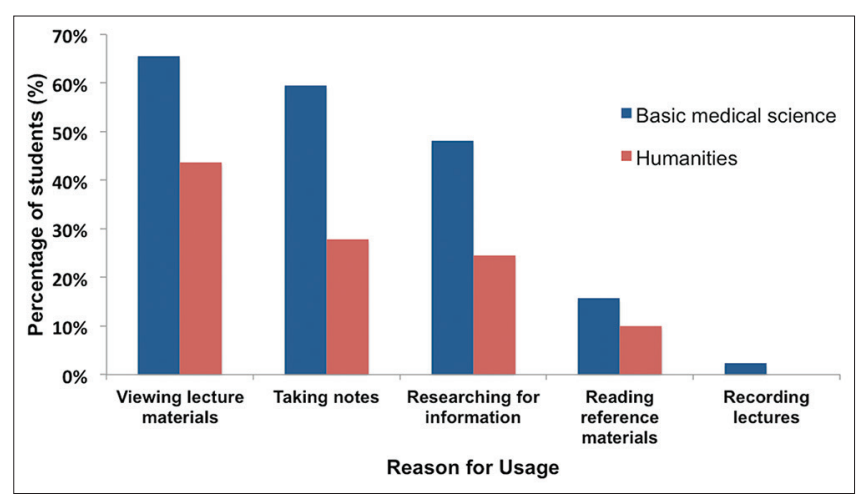

Figure 1: Reasons for the usage of electronic devices for learning purposes

reading reference materials [Figure 1]. For nonlearning purposes, $96(63.58 \%)$ used their electronic devices to access social media, $36(23.84 \%)$ for extracurricular activities, 57 (37.75\%) for accessing E-mails, 80 (52.98\%) for instant messaging, $53(35.10 \%)$ for entertainment, and $43(28.48 \%)$ for reading the news [Figure 2].

\section{Reasons for nonusage}

In basic medical science lectures, $90(23.14 \%)$ respondents reported they did not use electronic devices. Among the students who did not use electronic devices, over half $(52.2 \%)$ of them believed that usage of electronic devices did not facilitate their learning, and almost one-third $(31.1 \%)$ thought electronic devices were a source of distraction. Ten percent reported a preference of using printed notes over electronic devices.

Similarly in humanities lecture, 39 (20.53\%) respondents did not use electronic devices. Among these respondents, $24(61.54 \%)$ did not think the usage of electronic devices facilitate learning, while $12(30.77 \%)$ thought it was a distraction.

\section{DISCUSSION}

Results showed that preclinical medical students spent more time on their electronic devices for learning purposes in basic medical science lectures when compared with medical humanities lectures. On the other hand, more time was spent on nonlearning purposes in humanities lectures. This implies that preclinical medical students were less focused on the lecture content in humanities lectures when compared with science lectures. Medical students' criticism and skepticism against medical humanities teaching have been documented globally. In particular, medical students have suggested humanities teaching to be simplistic, uninteresting, ${ }^{[19]}$ and irrelevant to clinical practice. ${ }^{[20]}$ The differences in device usage

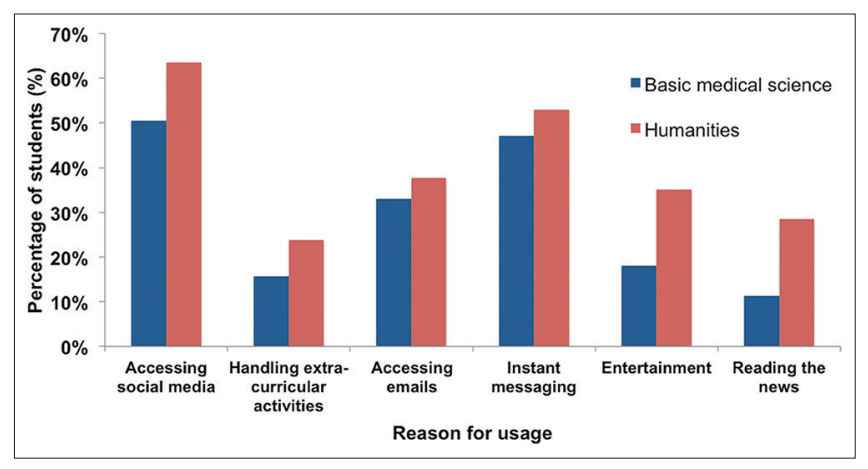

Figure 2: Reasons for the usage of electronic devices for nonlearning purposes

patterns between humanities and science lectures may be attributable to students' negative attitude toward humanities lectures. Since we did not assess students' views toward medical humanities, we were unable to draw any associations between learning attitudes and device usage. Nevertheless, the results from this study clearly demonstrated a disparity in device usage and attentiveness between science and humanities lectures. Further studies to assess how lecture content affect electronic device usage are warranted.

Students admitted through the non-JUPAS scheme spent significantly more time on learning using their electronic devices than JUPAS students during basic science lectures. JUPAS students are admitted to medical school from local schools whereas non-JUPAS students are admitted from international schools or overseas schools. English is a second language to the majority of Hong Kong students, and the exposure to English is less in local secondary schools when compared with international schools. ${ }^{[21]}$ Hence, non-JUPAS students are likely to have higher English ability than their JUPAS counterparts. Non-JUPAS students' language ability may enable them to make better use of electronic resources, which are mostly in English. Language could be a major contributing factor to the difference in electronic device usage observed in JUPAS and non-JUPAS students.

In basic medical science lectures, the year of study also had a significant effect on the time of usage for nonlearning purposes. Year 1 medical students spent significantly more time on nonlearning purposes on their electronic devices when compared with year 2 and 3 students. A previous study demonstrated that medical student seniority was associated with differences in concentration levels in class. The authors proposed that students being taught by different lecturers in different years may contribute to the disparity in attention levels. ${ }^{[22]}$ Our data revealed that aside 
Hui, et al.: Medical students' mobile device usage

from attentiveness in lectures, medical students' year of study has an effect on electronic device usage as well.

Overall, the usage rate of electronic devices in lectures was high. The usage rate was $76.86 \%$ in basic medical science lectures and $79.47 \%$ in humanities lectures. Certain students did not use electronic devices in the lectures, and the most common reason was they thought the devices did not facilitate their learning. Personal factors such as a preference for hand-written notes also contributed to the students' views on electronic devices in learning.

It was noted that many students used their electronic devices for multiple tasks and some students used their devices simultaneously for learning and nonlearning purposes. Multitasking on electronic devices is prevalent and has been reported in the literature. ${ }^{[2]}$ However, the actual effect of multitasking on learning has not been quantified. Further studies are needed to look into the pattern of multitasking on electronic devices and whether multitasking has any effect on learning efficiency.

In this study, students were required to retrospectively report their electronic device usage pattern during the lectures; therefore, recall bias could be present. Students may also be less willing to volunteer about their usage of electronic devices for nonlearning purposes due to social desirability bias. However, we administered the questionnaires immediately after the lectures and also did not collect any identifiable information; therefore, the recall and social desirability bias should be limited. The questionnaires were distributed to students after their lectures; therefore, the subjects did not include the absentees. It was observed that the attendance to humanities lectures was lower than in basic medical science lectures. The number of absentees could be related to students' attitude to the lecture type and could lead to selection bias. Future studies should aim to send out electronic questionnaires to all students, allowing collection of comprehensive data that includes absentees as well.

\section{CONCLUSIONS}

This study shows that lecture content has a significant impact on the duration and purpose of electronic device usage in preclinical medical lectures. Students spend more time on their devices for learning purposes in basic medical science lectures and more time on nonlearning purposes in humanities lectures. Mode of admission to medical school and the year of study have an effect on electronic device usage in basic medical science lectures. Appropriate interventions may be necessary to decrease the amount of time students spend on electronic devices for nonlearning purposes.

\section{Financial support and sponsorship \\ Nil.}

\section{Conflicts of interest}

There are no conflicts of interest.

\section{REFERENCES}

1. Roberts N, Rees M. Student use of mobile devices in university lectures. Australas J Educ Technol 2014;30:415-26.

2. Samson P. Deliverate engagement of laptops in large lecture classess to improve attentiveness and engagement. Computers in Education 2010;1:1-19.

3. Algeria DA, Boscardin C, Poncelet A, Mayfield C, Wamsley M. Using tablets to support self-regulated learning in a longitudinal integrated clerkship. Med Educ Online 2014;19:1-7.

4. Ibrahim NA, Salisu M, Popoola AA, Ibrahim TI. Use of smartphones among medical students in the clinical years at a medical school in Sub-Sahara Africa: A pilot study. J Mob Technol Med 2014;3:28-34.

5. Jang HW, Kim KJ. Use of online clinical videos for clinical skills training for medical students: Benefits and challenges. BMC Med Educ 2014;14:56.

6. Davis JS, Garcia GD, Wyckoff MM, Alsafran S, Graygo JM, Withum KF, et al. Use of mobile learning module improves skills in chest tube insertion. J Surg Res 2012;177:21-6.

7. Chan LK, Bridges SM, Doherty I, Ng ML, Jin J, Sharma N, et al. A qualitative study on how health professional students and their PBL facilitators perceive the use of mobile devices during PBL. Interdiscip J Problem Based Learn 2015;9:83-95.

8. Ortega-Rivas A, Saorín JL, de la Torre J, Elsheikha H. Touch-pad mobile devices for blended learning in immunology practicals. Med Educ 2013;47:518-9.

9. Mayfield CH, Ohara PT, O'Sullivan PS. Perceptions of a mobile technology on learning strategies in the anatomy laboratory. Anat Sci Educ 2013;6:81-9.

10. de Sena DP, Fabricio DD, Lopes MH, da Silva VD. Computer-assisted teaching of skin flap surgery: Validation of a mobile platform software for medical students. PLoS One 2013;8:e65833.

11. Kayser K, Ogilvie R, Borkenfeld S, Kayser G. E-education in pathology including certification of e-institutions. Diagn Pathol 2011;6 Suppl 1:S11.

12. Mueller PA, Oppenheimer DM. The pen is mightier than the keyboard: Advantages of longhand over laptop note taking. Psychol Sci 2014;25:1159-68.

13. Gaitsgory O, Burgess A, Mellis C. Opinion piece: "Medical students - Learning from textbooks or electronic media?" J Paediatr Child Health 2013;49:E370-2.

14. Bahner DP, Adkins E, Patel N, Donley C, Nagel R, Kman NE. How we use social media to supplement a novel curriculum in medical education. Med Teach 2012;34:439-44.

15. George DR, Dreibelbis TD, Aumiller B. How we used two social media tools to enhance aspects of active learning during lectures. Med Teach 2013;35:985-8.

16. George DR, Dreibelbis TD, Aumiller B. Google Docs and SurveyMonkey ${ }^{\mathrm{TM}}$ : Lecture-based active learning tools. Med Educ 2013;47:518. 


\section{Hui, et al.: Medical students' mobile device usage}

17. Wallace S, Clark M, White J. "It's on my iPhone:" Attitudes to the use of mobile computing devices in medical education, a mixed-methods study. BMJ Open 2012;2. pii: e001099.

18. Ellaway R. The informal and hidden curricula of mobile device use in medical education. Med Teach 2014;36:89-91.

19. Block MR, Coulehan JL. Teaching the difficult interview in a required course on medical interviewing. J Med Educ 1987;62:35-40.
20. Shapiro J, Coulehan J, Wear D, Montello M. Medical humanities and their discontents: definitions, critiques, and implications. Acad Med 2009;84:192-8.

21. Flowerdew J, Miller L. Student perceptions, problems and strategies in second language lecture comprehension. RELC J 1992;23:60-80.

22. Stuart J, Rutherford RJ. Medical student concentration during lectures. Lancet 1978;2:514-6. 
Hui, et al.: Medical students' mobile device usage

\section{APPENDIX - QUESTIONNAIRE USED IN THE STUDY}

\section{Medical Students' Usage of Mobile Devices Questionnaire}

Please answers the following questions according to the instructions

Please put a tick in the appropriate boxes

Please note that MOBILE DEVICES includes laptop or notebook computers, smartphones (e.g. iPhone, Galaxy Note, etc.), tablets (e.g. iPad, iPad mini, Galaxy Tab, etc.), and ebook readers, (e.g. Kindle, NOOK, etc.), etc.

1. What is your gender?

- Male

- Female

2. What is your year of study?

- MBBS I

- MBBS II

- MBBS III

3. Through which of the following did you enroll into this program?

- JUPAS

- Non-JUPAS (Previous education level: Secondary/Bachelor/Master/Doctoral)

4. Please specify the number of mobile devices you own:

5. To which of the following categories does the lecture you have just attended belong?

- Medical Humanities

6. Did you use any mobile device (s) in the lecture you just attended?

- Yes

- No

(If yes, please proceed to question 8; if no, please proceed to question 7)

7. Why did you not use a mobile device in the class you just attended?

- Mobile devices do not facilitate my learning

- Mobile devices distracts me

- The lecturer did not allow the use of mobile device

- Others (Please specify:

(Please proceed to question 12)

8. Please indicate the device (s) you used in class:

(You can choose more than 1 option)

- Laptop

- Smartphone

- Tablet

- Ebook reader

- Others (Please specify:

9. What did you use your device for? (You can choose more than 1 option)

- Learning purposes

- Viewing lecture materials 
- Taking notes

- Searching for information relevant to the lecture content

- Viewing reference material, e.g. ebooks, journals

- Others (Please specify:

- Non-learning purposes

- Social Media (e.g. Facebook)

- Handling extracurricular activities matters

- E-mail

- Instant messaging

- Entertainment (e.g. YouTube, gaming)

- Reading the news

- Others (Please specify:

10. Approximately how much time did you use your mobile devices for learning purposes in the lecture? minutes

11. Approximately how much time did you use your mobile devices for nonlearning purposes in the lecture? minutes

12. To what extent do you agree with the following statement?

"Mobile device (s) facilitate your learning during lectures."

- Strongly Disagree

- Disagree

- Neutral

- Agree

- Strongly Agree

13. To what extent do you agree with the following statement?

"Mobile devices should not be used for noneducational purposes during lecture."

- Strongly Disagree

- Disagree

- Neutral

- Agree

- Strongly Agree

14. To what extent do you agree with the following statement?

"Use of mobile device (s) during lectures should be regulated."

- Strongly Disagree

- Disagree

- Neutral

- Agree

- Strongly Agree

End of questionnaire. Thank you for taking part in this research study.

Please hand in this questionnaire together with the consent form to any of our teammates. 